\title{
O processo administrativo-sanitário como instrumento de efetividade das ações de vigilância sanitária
}

\section{The administrative-sanitary process like instrument of effectiveness of the actions of the sanitary vigilance}

\section{El proceso administrativo-sanitario como instrumento de efectividad de las acciones de la vigilancia sanitaria}

\author{
Joedson de Souza Delgado ${ }^{1}$
}

\section{RESUMO}

Analisa-se o processo administrativo-sanitário oriundo da Lei n. 6.437/1977, suas formalidades e tramitação no contexto da vigilância sanitária. Aborda-se a complementação de outras regras jurídicas em sentido amplo para caracterizar adequadamente uma situação como infração sanitária. Destaca-se a importância da sistematização do Direito Sanitário sancionador com observância aos primados da ampla defesa e do contraditório em face do atributo da coercibilidade presente no poder de polícia. Revisa-se o material bibliográfico acerca do tema, com ênfase na doutrina administrativa sanitária e estudam-se os elementos do poder normativo e do poder de fiscalização, percorrendo a edição de regramentos técnicos que estabelecem condutas obrigatórias, vedadas ou permitidas. Conclui-se que a norma processual, prevista na Lei n. 6.437/1977, contempla um conjunto de medidas que realiza a prevenção dos riscos e a proteção dos danos à saúde com a responsabilidade legal diante do

1 Especialista em Direito Sanitário, Fundação Oswaldo Cruz (Fiocruz - Brasília). Analista Administrativo na Agência Nacional de Vigilância Sanitária (Anvisa). Administrador e Advogado. Brasília/DF - Brasil. Lattes: http://lattes.cnpq.br/3574246621121538 descumprimento ao ordenamento jurídico-sanitário, mas que alguns institutos devem ser atualizados/ revistos, assim como apurado o modelo de cobrança administrativa e judicial das multas sanitárias.

Palavras-chave: Processo legal; vigilância sanitária; infração sanitária; poder de polícia; responsabilidade legal.

\section{ABSTRACT}

Analyzed the administrative-sanitary process from the Brazilian Law n. 6.437/1977, his rules and procedure in the context of the sanitary vigilance. Approached the complementation of other juridical rules in a wide sense to characterize adequately a situation as sanitary infraction. Stands out the relevance of the systematization of Sanitary Law punitive, with observance in the priority of the ample defense and the contradictory in front of the attribute of present repression in the power of the police. Revised the bibliographical material over of the topic, emphatically in the administrative sanitary doctrine and study the elements of the normative power and of the power of inspection, crossing the edition of technical regulations that establish compulsory 
conduct, prohibited or allowed. We end that the procedural norm, foreseen in Brazilian Law n. 6.437/1977, contemplate a set of measures that realize the prevention of the risks and the protection of the damages to the health, with the legal responsibility against the breach of the ordering juridical-sanitary, although some Institutes must be updated/reviewed, well as purifying the model of administrative and judicial collection of the sanitary fines.

Keywords: Legal process; health surveillance; sanitary infraction; police power; liability, legal.

Resumen: Se analiza el proceso administrativo-sanitario proveniente de la Ley brasileña n. 6.437/1977, sus reglas y tramitación en el contexto de la vigilancia sanitaria. Se aborda la complementación de otras reglas jurídicas en un sentido amplio para caracterizar adecuadamente una situación como infracción sanitaria. Se destaca la importancia de la sistematización del Derecho Sanitario sancionador con observancia en la primacía de la amplia defensa y del contradictorio frente al atributo de represión presente en el poder de la policía. Se revisa el material bibliográfico acerca del tema, con énfasis en la doctrina administrativa sanitaria y se estudian los elementos del poder normativo y del poder de fiscalización, recorriendo la edición de normativas técnicas que establecen conductas obligatorias, prohibidas o permitidas. $\mathrm{Se}$ concluye que la norma procesal, prevista en la Ley brasileña n. 6.437/1977, contempla un conjunto de medidas que realizan la prevención de los riesgos y la protección de los daños a la salud, con la responsabilidad legal frente al incumplimiento del ordenamiento jurídicosanitario, aunque algunos Institutos deben ser actualizados/revisados, así como apurar el modelo de cobro administrativo y judicial de las multas sanitarias.

Palabras clave: Proceso legal; vigilancia sanitaria; infracción sanitaria; poder de policía; responsabilidad legal.

\section{INTRODUÇÃO}

$\mathrm{O}$ presente artigo aborda o percurso sistematizado das atividades especializadas de regulação, inspeção, fiscalização e controle sanitário concernente às infrações estabelecidas na Lei n. $6.437 / 1977^{1}$, instrumentalizada pelo processo administrativo-sanitário (PAS), conducente a decisões administrativas (atos administrativos) de cunho punitivo. Cuida-se de atribuição funcional dos servidores autuantes da Agência Nacional de Vigilância Sanitária (Anvisa) e, por competência concorrente, das Vigilâncias Sanitárias (Visas) estaduais, municipais e distrital.

A abordagem leva em conta o campo de atuação da vigilância sanitária sob o pálio da efetivação da garantia de uma vida com saúde física, mental e social, para os fins e efeitos da Lei n 8.080/1990² que constitui o Sistema Único de Saúde (SUS). Por isso mesmo, o legislador atribuiu poderes normativos gerais, expressos de maneira ampla, à Anvisa nos termos do art. $8^{\circ}$, caput, da Lei n. 9.782/19993. "incumbe à agência, respeitada a legislação em vigor regulamentar, controlar e fiscalizar os produtos e serviços que envolvam riscos à saúde pública”.

Por conseguinte, enquadra-se o ilícito sanitário ao correspondente arcabouço legal no intuito de prevenir qualquer atividade de pessoas naturais ou jurídicas que possam representar riscos à saúde 4 .

E para lograr o intento almejado, a legislação pertinente assegurou ao autuado uma série de 
garantias insertas no PAS para o adimplemento de normas e padrões sanitários.

As instituições sanitárias (Anvisa e Visas), por intermédio de seus agentes investidos do poder de polícia, averiguam a ocorrência do ilícito; sendo necessário, autuam (lavram o auto de infração); e, sendo devidas, as autoridades sanitárias credenciadas (singular ou colegiada) punem. De toda sorte, a transgressão das normas sanitárias (ação ou omissão) incide na cogência da Lei n. 6.437/1977', suscitando assim a aplicação da lei ao fato.

Ocorre que, não obstante a permissão legal dada à Anvisa e às Visas de normatizar suas ações e serviços, resta perquirir se os mecanismos usuais de controle e fiscalização permitem sua efetividade, legitimidade e racionalidade na execução dessas atividades, de modo a permitir um amplo exercício da polícia administrativa. Assim, faz-se pertinente analisar o contexto normativo de atuação da vigilância sanitária, no que tange às infrações à legislação sanitária federal quanto àquelas características e sua sistemática processual.

Reuniram-se obras de caráter inter e multidisciplinar da vigilância sanitária, tais como, pesquisa em livros técnicos e fontes em órgãos de governo, bem como análise da legislação pertinente, publicados em meio impresso ou divulgados em sítio eletrônico. O recorte temporal compreende o ano de concepção da Anvisa (1999) até o presente, justificando-se pelas dificuldades e limitações do levantamento bibliográfico em data anterior e pelo expressivo número de publicações ordenadas no período.

O artigo foi dividido em quatro partes, inicialmente será abordado o viés da saúde humana, no contexto da sua tutela jurídica, para então analisar o desenvolvimento e os efeitos do ato punitivo no bojo do processo sanitário, pelos meios processuais de defesa administrativa e, por fim, algumas considerações acerca do encerramento do processo.

\section{CONSIDERAÇÕES SOBRE A PROTEÇÃO DA SAÚDE PÚBLICA}

Este capítulo subdivide-se em três partes. $\mathrm{Na}$ primeira, aborda-se a relação do direito à saúde com o Direito Sanitário e com a vigilância sanitária. $\mathrm{Na}$ segunda, adentra-se nos aspectos gerais relacionados ao ato normativo e ao processo de fiscalização ante as violações do preceptivo sanitário. Na terceira, analisa-se o instrumento processual apto a prevenir ou reprimir o ilícito sanitário.

\section{Direito à saúde, Direito Sanitário e vigilância sanitária}

O direito à saúde - timbrada como direito social - refere-se, dentre outros aspectos, ao valor da igualdade entre as pessoas cujo bem jurídico, direito à vida, encontra-se situado na categoria dos direitos fundamentais, constitucionalmente tutelado, de forma não exaustiva, porquanto pode recepcionar tratados internacionais em que a República Federativa do Brasil seja parte, conforme prescreve o artigo $5^{\circ}$, $2^{\circ}$, da Constituição Federal ${ }^{5}$. Nesse sentido, Mapelli Júnior, Coimbra e Matos ${ }^{6}$ explanam:

[...] que a Constituição Federal, de um lado, elevou o acesso à saúde à categoria de direito subjetivo público - exigível judicialmente, inclusive -; e de outro, imputou ao Estado um rol de deveres derivados desse direito. [...]

É interesse de toda a sociedade que todos os seus membros, indistintamente, tenham acesso amplo aos serviços de saúde, de modo que a higidez sanitária dos aparelhamentos 
públicos destinados à prestação de tais serviços, por exemplo, se constitui em um interesse difuso a ser tutelado e fiscalizado pelos órgãos de controle.

Já o Direito Sanitário ocupa-se das normas que protegem a saúde humana, compreendida por duas vertentes doutrinárias que reconhecem sua autonomia do Direito Administrativo, em razão de possuir preceptivos, princípios e categorias jurídicas próprias, e a outra, dos administrativistas italianos, que se opõe a este entendimento ${ }^{7}$.

\section{Rodrigues $^{8}$ leciona que}

O nascimento do direito sanitário só se torna possível quando a ciência jurídica abandona seus paradigmas exclusivamente individualistas e patrimonialistas, passando a assumir a relevância da dimensão coletiva do homem para sua plena proteção jurídica e a valorização de vários bens e direitos que não possuem equivalente econômico.

E arremata Carvalho, Machado e Timm?:

Em outras palavras, direito sanitário positivo é formado pelo plexo de normas jurídicas que regulam a produção de medicamentos, alimentos, fumo, bebidas alcoólicas, barreiras sanitárias, vigilância sanitária, taxas sanitárias e serviços relativos à saúde.

Desse modo, as ações desenvolvidas pela vigilância sanitária - entendida como um campo da saúde coletiva - associam-se aos determinantes sociais que, muitas vezes, não guarda relação com o setor saúde.

A Conferência Mundial sobre Determinantes Sociais da Saúde, ocorrida no Rio de Janeiro entre dias 19 e 21 de outubro de 2011, convocada pela Organização Mundial da Saúde (OMS), teve como objetivo compartilhar experiências em lidar com os desafios apresentados pelas desigualdades no campo da saúde e mobilizar os países para o compromisso de melhorar as condições da saúde e de bem-estar, reduzir as iniquidades e promover o desenvolvimento social além do campo da saúde.

Firme neste entendimento, Ferreira ${ }^{10}$ expõe que:

[...] a vigilância sanitária é uma das formas mais complexas da saúde pública, pois suas ações de natureza eminentemente preventiva perpassam todas as práticas médico-sanitárias: promoção, proteção, recuperação e reabilitação da saúde. Além disso, atua sobre fatores de risco associados a produtos, insumos e serviços relacionados com a saúde, o ambiente e o trabalho com a circulação internacional de cargas e pessoas.

A partir de 1930, de forma geral, a sociedade brasileira passou por uma transformação econômica e política com o advento da expansão industrial que acarretou mudanças nos hábitos de consumo de mercadorias, bens e serviços, além de processos produtivos tecnológicos geradores de risco sanitário $^{11}$. Verifica-se, desde então, que a evolução dessas circunstâncias sociais amoldou a forma hodierna das condições de saúde no país.

Nesse sentido, o Estado, reconhecendo a patente fragilidade do indivíduo, consignou no art. 200, inc. I a VIII, da Lei Fundamental, a expressão vigilância sanitária como uma das ações do SUS com foco no bem-estar e na justiça social. Para tal, o $\$ 1^{\circ}$ do art. $6^{\circ}$ da Lei n. 8.080/1990² definiu o papel e a abrangência da vigilância sanitária como

[...] um conjunto de ações capaz de eliminar, diminuir ou prevenir riscos à saúde e de intervir nos problemas sanitários 
decorrentes do meio ambiente, da produção e circulação de bens e da prestação de serviços de interesse da saúde, abrangendo:

I - o controle de bens de consumo que, direta ou indiretamente, se relacionem com a saúde, compreendidas todas as etapas e processos, da produção ao consumo; e

II - o controle da prestação de serviços que se relacionam direta ou indiretamente com a saúde.

$\mathrm{O}$ dispositivo em comento atribui à vigilância sanitária a competência normativa e reguladora. Autoriza-se, assim, a edição de normas, de que resulta a regulação da atividade de produção e de comercialização, exercida por intermédio da inspeção/vistoria sanitária com a prevenção de doenças e agravos à saúde humana, incursa na alínea 'a' do inc. I do art. $6^{0}$ da Lei n. 8.080/1990², nos seguintes termos:

Art. $6^{\circ}$ Estão incluídas ainda no campo de atuação do Sistema Único de Saúde (SUS):

I - a execução de ações:

a) de vigilância sanitária; [...]

Por seu turno, o art. $3^{\circ}$ da Lei n. 9.782/1999³ criou a Anvisa, autarquia em regime especial, que substituiu a antiga Secretaria Nacional de Vigilância Sanitária integrante do Ministério da Saúde, tendo por finalidade institucional fixar diretrizes de atuação, controlar e fiscalizar os produtos, substâncias e serviços que envolvam riscos à saúde pública.

Registra-se, ainda, as variadas atribuições da Anvisa, contidas no art. $7^{\circ}$ com destaque para o inc. III $^{3}$ :
Art. $7^{\circ}$ Compete à Agência proceder à implementação e à execução do disposto nos incisos II a VII do artigo $2^{\circ}$ desta Lei, devendo:

\section{$[\ldots]$}

III - estabelecer normas, propor, acompanhar e executar as políticas, as diretrizes e as ações de vigilância sanitária; $[\ldots]$

É importante assinalar que a Anvisa poderá delegar aos Estados, aos Municípios e ao Distrito Federal a execução de atribuições que the são próprias, ressalvadas as exceções abrigadas no art. $7^{\circ}, \S 1^{\circ}$, da Lei n. 9.782/1999³. Acrescenta-se que os Municípios podem editar normas suplementares à legislação federal e estadual, em face de critérios adequados com a realidade local, como medida de aplicação e execução das ações e serviços de vigilância sanitária.

Como se percebe no dispositivo legal acima transcrito, as normas sanitárias editadas pela Anvisa decorrem do fenômeno nominado delegificação ou deslegalização - subespécie da delegação legislativa, oriunda do Direito Francês. Trata-se da degradação da hierarquia normativa (descongelamento da classe preceptiva) das leis sanitárias que, por opção do próprio legislador, deixa de ser regulada por lei e passa a seara do ato administrativo normativo, caso das Resoluções da Diretoria Colegiada (RDC) fragmento da lei federal autorizadora deste tipo de regulamentação ${ }^{12}$.

Nesse particular, Albuquerque ${ }^{13}$ escreve acerca do caráter derivado da função normativa da vigilância sanitária que

[...] parte-se dos pressupostos maiores 
da força normativa da constituição e da eficácia imediata dos direitos fundamentais constitucionalmente previstos para admitir que a Administração possa, em certos casos, fundamentar sua atividade normativa diretamente do texto constitucional, prescindindo da mediação do Poder Legislativo.

Do exposto, é cabível impor sanções pelo motivo da prática de infrações sanitárias consignado em três planos: constitucional (art.197) $)^{5}$, legal stricto sensu (Lei n. 6.437/1977) ${ }^{1}$ e regulamentar (RDC).

Saliente, todavia, que a função normativa das instituições sanitárias, tão somente, restringe a regulação de aspectos técnicos e econômicos devido à competência outorgada por lei para expedir mandamentos, haja vista o atendimento das múltiplas, dinâmicas e sofisticadas demandas da vida contemporânea, sujeitas a potenciais riscos sanitários.

\section{A vigilância sanitária como atividade administrativa}

Além do poder normativo, as ações de controle sanitário desenvolvido pela Anvisa e pelas Visas também contemplam as funções executiva (poder de fiscalização) e judicante (solução de controvérsias) e compõem uma das formas de intervenção pelo Estado, nos moldes clássicos do poder de polícia estatal no campo da saúde pública.

A função executiva permite à Anvisa e às Visas que fiscalizem e apliquem sanções aos agentes regulados com base nos quatro ciclos do poder de polícia: legislação, consentimento, fiscalização e sanção.

Assim, percebeu Guerra ${ }^{14}$ :
Nesse sentido, a Anvisa detém poder de polícia sanitária, que consiste em um conjunto de intervenções no sentido de disciplinar a atuação das atividades afetas a sua área, objetivando prevenir ou reprimir pertubações à saúde pública.

Já a função judicante refere-se à capacidade de solução de controvérsias das Visas e abrange a mediação, a conciliação e a arbitragem regulatória. Salienta-se que essa função não se confunde com a função jurisdicional da Justiça. Aliás, em decorrência da inafastabilidade do controle jurisdicional encartado no inc. XXXV do art. $5^{\circ}$ do Magno Texto Republicano ${ }^{5}$ enseja, em certa medida, a possibilidade de revisão dos atos, podendo uma decisão judicial substituir uma decisão administrativa. Por ora, não será objeto de estudo a reflexão do uso da função judicante, na busca de uma administração consensual segundo conhecimentos técnico-científicos de que são dotadas.

No que tange à função executiva, a Anvisa dispõe do exercício de poder de polícia sanitária consoante se depreende do art. $7^{\circ}$ e $8^{\circ}$ da Lei n. 9.782/1999³. Assim, definido o limite de competência, a entidade poderá condicionar e restringir abusos do setor regulado em relação ao Estado e, consequentemente, à coletividade.

Derivado do art. 174 do Pacto Fundamental ${ }^{5}$, a função de fiscalização significa verificar o cumprimento dos preceitos das normas e procedimentos da vigilância sanitária. Nestas condições, uma multiplicidade de espécies normativas (leis, medidas provisórias, decretos, portarias, resoluções e instruções normativas) define, orienta e determina qual seja o complexo de atividades da vigilância sanitária e cuja inobservância cabe averiguar, enquadrar, dar-lhe autoria e decidir administrativamente segundo os ditames sanitários, emitindo juízo de valor, sem o 
qual decorreria impunidade, agravada por todos os seus indesejáveis efeitos.

A rigor, as atividades de vigilância sanitária situam-se no campo social do Direito Administrativo, de natureza coercitiva, perceptível a sua ação fiscalizatória na prestação de serviço público, e no campo do Direito Público Internacional, cuja ação de controle sanitário figura em portos, aeroportos, fronteiras e recintos alfandegados.

Ainda de acordo com Guerra ${ }^{14}$ :

A regulação desenvolvida pela Anvisa não se enquadra na ideia de haver imperiosa regulação estatal descentralizada, contra barreiras às pressões políticas e sociais, estruturada para promover o equilíbrio sistêmico. A Anvisa não carece de maleabilidade de normas legiferantes [...] para agir e coibir os excessos eventualmente cometidos pelos agentes regulados [...] A função de polícia sanitária e de salubridade é uma das primeiras atividades realizadas pelo Estado para assegurar a sua existência na ordem interna e externa.

Com base nessa premissa, a Anvisa compartilha a competência de averiguar os atos ou fatos contrários às normas sanitárias em decorrência do controle a qual é atribuída pela Carta Federal vigente ${ }^{5}$ e pela legislação ordinária específica ${ }^{1}$ em conjunto com as prerrogativas de função de seus agentes públicos dotados do poder de polícia administrativa.

Quanto à atividade de fiscalização da vigilância sanitária, leciona Aith ${ }^{15}$ que "[...] a Lei Federal n. 6.437/1977, que dispõe sobre as infrações sanitárias, prevê sanções e abrange procedimento específico para os processos administrativos sanitários que apuram tais infrações”. Significa, então, afirmar que a Anvisa e as Visas valem-se das sanções ali previstas aos transgressores, com a lavratura do
Auto de Infração Sanitária (AIS), perscrutando as razões da conduta dentro do PAS.

Por conseguinte, a Lei n. 6.437/1977 adnumera, de forma genérica, os ilícitos à legislação sanitária federal acompanhada de medidas preventivas assecuratórias destinadas a impedir a fixação ou a continuidade de atividades consideradas lesivas à saúde pública. Assim sendo, perfaz as ações de inspeção e fiscalização em verificar o cumprimento das normas sanitárias e, no eventual descumprimento, apontar a ilicitude cometida, sua autoria e a legislação aplicável ao caso, desencadeando procedimentos subsequentes.

Justen Filho" ${ }^{16}$ ensina que esse poder "é a competência para disciplinar o exercício da autonomia privada para a realização de direitos fundamentais e da democracia, segundo os princípios da legalidade e da proporcionalidade.”.

De fato, a função de polícia sanitária, enquanto poder de polícia, confere ao agente estatal atributos (discricionariedade, autoexecutoriedade e exigibilidade) que impõem ao particular uma restrição e/ou condicionamento, mediante lei, de certos atos contrários ao interesse coletivo, ou até mesmo abusos em relação ao Estado.

Importa registrar que, para Guerra ${ }^{14}$, o poder de polícia sanitária define-se como "[...] um conjunto de intervenções no sentido de disciplinar a atuação das atividades afetas a sua área, objetivando prevenir ou reprimir perturbações à saúde pública.”.

Constitui, portanto, prerrogativa da fiscalização sanitária barrar a conduta que expõe em risco a integridade ou a vida dos cidadãos, cuja atuação se volta para o interesse público. Para tanto, faz-se necessário à ordenação do poder punitivo estatal. 
Logo, o processo - não mais o ato administrativo - é o instrumento capaz de identificar as hipóteses de desobediência às normas sanitárias, enquadrá-la no tipo previsto e dar-lhe autoria, visando sua punição em face da Lei n. 6.437/1977'. A sistematização surge como mecanismo de controle do exercício estatal perante o autuado, concretizado sucessivamente por atos separados, porém correlacionados e concatenados das ideias, fatos e argumentos técnicojurídicos para aquilatar a materialidade da infração sanitária e sua autoria.

\section{O devido processo legal administrativo}

Incumbem às instituições sanitárias, a instauração do PAS constatada a infringência à legislação sanitária, por pessoas físicas ou jurídicas, por ato comissivo ou omissivo, quanto aos aspectos de inspeção das instalações físicas; das etapas e processos de produção e consumo; e dos bens e serviços direta ou indiretamente relacionados com a saúde.

\section{Assevera Hirsch ${ }^{17}$ :}

Quando o agente de vigilância sanitária, ao se deparar com infração sanitária, e, julgando a situação de fato, entender oportuna e conveniente a lavratura de auto de infração, ocorrerá abertura de processo administrativo-sanitário, pelo órgão fiscalizador, contra o autuado. Rege a matéria a Lei $\mathrm{n}^{0}$ 6.437/77.

A observância da forma instrumentalizada quanto à apuração da infração sanitária possibilita que 0 feito sanitário granjeado pela Lei $n$. 6.437/1977 sirva, para Zymler ${ }^{18}$, "[...] como forma de harmonizar a necessidade de interferência do Estado nos subsistemas sociais e a improficuidade do direito substantivo".

Constroem-se, assim, três perspectivas acerca da utilidade procedimental. A primeira refere-se à garantia de direitos subjetivos, instituídos em favor dos administrados e instrumento de contenção da atuação estatal; a segunda, a possibilidade de recorrer, produzir provas, contrapor argumentos etc. de uma decisão desfavorável por intermédio de teses jurídicas; a terceira compreende a interação popular no direito de petição - mandado de segurança, habeas data etc. - como meio de controle da Administração Pública, bem como a participação em processos administrativos à consecução da vontade estatal eleição partidária, audiência pública etc. ${ }^{18}$.

A sistematização do Direito Sanitário denota que o PAS é um mecanismo expedito, utilizado com maestria pela Anvisa e pelas Visas, na salvaguarda do direito à saúde ameaçada ou maculada por ato de particular.

Ressalta-se, por outro lado, que não existe consenso doutrinário entre as terminologias - processo administrativo ou procedimento administrativo. Entretanto, adota-se a clássica acepção etimológica de que o processo significa "marcha avante", do latim procedere, ir adiante. Assim, para Olbertz" ${ }^{19}$, "procedimento, em sentido estrito, é sucessão concatenada de atos voltados a um objetivo final. Processo, por sua vez, é o procedimento qualificado pela participação dialética dos interessados". Em outras palavras, processo é a coordenação de atos, em razão de atividade administrativa, enquanto, procedimento é a forma concreta com que se realiza a formação complexa de atos que se sucedem.

A partir disso, infere-se que o processo sanitário é justamente o mecanismo específico de que se vale a vigilância sanitária para exercer a função executiva, por meio das regras do direito material (lei substantiva) e processual (lei adjetiva) fixadas, simultaneamente, na Lei n. 6.437/19771 , podendo se 
albergar em leis subsidiárias, tal como a generalidade da Lei do Processo Administrativo Federal ${ }^{20}$.

Destarte, a Lei n. $6.437 / 1977^{1}$ descreve as infrações sanitárias como ações típicas, antijurídicas e culpáveis (este último não é requisito indispensável para caracterizar o tipo punível, conforme aponta o art. $3^{\circ}, \S 1^{\circ}$, da norma em estudo) e o PAS é o meio processual de apuração que contém o rito de julgamento, às formalidades, os termos e os atos processuais $^{21}$.

É válido destacar que, como instituto jurídico que norteia as regras de saúde pública, a Lei $\mathrm{n}$. 6.437/1977 é obsoleta, anterior à promulgação da Carta Maior ${ }^{5}$, cujas atualizações se limitaram a mudanças pontuais.

Particularmente, os agentes públicos exercem suas funções por intermédio de leis específicas, nos cargos de especialista em regulação e vigilância sanitária/fiscal sanitário/fiscal de controle sanitário/ fiscal de saúde pública/técnico de fiscalização sanitária, etc. ou, ainda, por servidores credenciados. Ademais, a Lei n. 6.437/1977' denominam de "servidor autuante" ou, apenas, "autuante", cujas atribuições típicas permitem adotar as providências necessárias ao cumprimento do preceito sanitário, se verificado a transgressão.

Nesta linha de agir, o PAS objetiva discutir o mérito da exigência constante do AIS com a oitiva do autuado em contraposição as razões do autuante, a quem imprime a convicção acerca do restabelecimento ou adequação à norma diante do conjunto probatório.

\section{O PROCESSO ADMINISTRATIVO- SANITÁRIO E SUAS NUANCES}

No tópico anterior, demonstrou-se a relevância do tema no atual contexto do direito à saúde, valendo-se de medidas cogentes que sustentem sua concretização. Menciona-se a seguir, a estrutura, de natureza organizacional e/ou funcional do PAS e seus desdobramentos, delimitando o campo de vinculação do ato ao processo.

\section{A decisão no processo administrativo-} sanitário - estrutura e efeitos

No PAS há uma acusação que permite caracterizar a autoria e a materialidade de uma infração; por meio dela aplicam sanções de que decorrem limitações, restrições ou perda de direitos, enfim, decidem interesses.

Para alcançar o intento suso descrito, o art. 10 da Lei n. 6.437/1977 elenca quarenta e um incisos em que tipifica situações para quem incidiu ou colaborou na ocorrência da infração sanitária, seja por ação ou omissão, ressalvada a excludente da imputabilidade (força maior, eventos naturais e circunstâncias imprevisíveis) inserta no $\S 2^{\circ}$ do art. $3^{\circ}$, do diploma em estudo.

Sob o ângulo jurídico, a estrutura da Lei n. 6.437/1977 compreende a sanção como elemento característico de cada um dos incisos do art. 10 estando, assim, catalogadas as infrações administrativas sanitárias e as correspondentes sanções. Portanto, infração e pena, em abstrato, possuem identidade de fundamento legal, vale dizer, mesmo artigo e inciso devem constar do preenchimento do auto de infração quanto ao enquadramento do ilícito sanitário.

Kelsen"2 entende que "sanções são atos coercitivos, e sanções infligidas a indivíduos por órgãos administrativos certamente são interferências no patrimônio, na liberdade e mesmo na vida dos cidadãos". 
Atente-se, desde logo, que, para pespegar sanção à conduta tida como ilícita, deve haver a valoração das provas pelos autuantes e autoridades sanitárias competentes (singular ou colegiada), expressando de forma fundamentada e explicitando o raciocínio proferido na decisão.

A intenção é prevenir ou reprimir o ilícito sanitário que não se pauta necessariamente por circunstâncias de gradação, também denominado de ordem legal de penalidades. Vale dizer, as punições são infligidas discricionariamente pela autoridade sanitária, sendo desnecessária a cominação de uma penalidade mais leve antes da mais grave.

Neste contexto, exsurge a graduação da pena dentro da moldura legal prevista que traz elementos balizadores que mensuram a pena, tais como atenuantes e agravantes, a primariedade ou a reincidência do infrator, a gravidade da infração e o porte econômico do infrator.

No esboço de Dias $^{23}$ consiste em:

Havendo concurso de circunstâncias atenuantes e agravantes, a aplicação da pena será considerada em razão das que sejam preponderantes, ou seja, a pena serve para aproximar-se do limite indicado pelas circunstancias preponderantes, entendendose como tal as que resultem dos motivos de determinada infração sanitária, da personalidade do agente e da reincidência.

Significa, na prática, que a autoridade sanitária prioriza as condições subjetivas em detrimento das objetivas no deslinde de casos que apresentam concurso de circunstâncias agravantes e atenuantes.

Entende-se que o autuado possuía antecedentes traduzidos em inúmeros autos de infração ainda pendentes de julgamento, era reincidente (agravante genérica), todavia confessou, imediatamente, a autoria do ilícito sanitário e, logo após, procurou reparar ou minorar as consequências do ato danoso/ lesivo à saúde pública (circunstância atenuante). Nesse caso, os maus antecedentes são levados em conta na aplicação da pena-base de R $\$ 2.000,00$ (dois mil reais) para infrações sanitárias leves, $\mathrm{R} \$$ 75.000,00 (setenta e cinco mil reais) para infrações graves e $\mathrm{R} \$ 200.000,00$ (duzentos mil reais) para infrações gravíssimas, em face da circunstância de confissão que não pôde ser compensada em virtude da preponderância da circunstância agravante da reincidência sobre a atenuante de confissão espontânea, atendendo ao gizado no art. $9^{\circ}$ da Lei n. $6.437 / 1977^{1}$.

Resta por fim advertir que, as sanções de índole sanitária devem refletir a reprovabilidade (serem adequadas à gravidade) da infração cometida no caso concreto.

As sanções erigidas no art. $2^{\circ}$, inc. I a XI-A da Lei n. 6.437/1977' são: advertência; multa; apreensão de produto; inutilização de produto; interdição de produto; suspensão de vendas e/ ou fabricação de produto; cancelamento de registro de produto; interdição parcial ou total do estabelecimento; proibição de propaganda; cancelamento de autorização para funcionamento de empresa; cancelamento do alvará de licenciamento de estabelecimento; intervenção no estabelecimento que receba recursos públicos de qualquer esfera.

De tais medidas elencadas, ressai a finalidade da lei em corrigir atitudes ou inibir danos/lesões que afetam direta ou indiretamente a vida dos cidadãos.

De outra parte, não afasta o autor de uma infração sanitária da responsabilidade civil e criminal ou a prática de atos de improbidade administrativa, 
decorrente daqueles que atentam contra os princípios da administração pública, tal como, o comportamento de agente público que retarda ou deixa de praticar, indevidamente, a adoção de medidas de ofício destinado a velar a saúde pública.

No exame da matéria, verifica-se na Lei $n$. $6.437 / 1977^{1}$ que o autuante manifestará em dez dias com o subsequente julgamento da conduta pela autoridade sanitária competente do órgão/ entidade federal, estadual, municipal, distrital ou por delegação de competência por meio de convênios, conforme plasmado no art. $22, \S 2^{\circ}$, da lei mencionada.

Nesse momento, são examinados os fatos concretos e particulares (direito subjetivo), bem como as questões de direito (direito objetivo).

Em caso de condenação a uma das punições cabíveis, o infrator poderá recorrer da decisão monocrática com o manejo da defesa ou impugnação, no prazo de até quinze dias.

Situação estatuída na Lei n. 6.437/1977 (art. 30, parágrafo único), a retratação ou reconsideração pode ser exercida pela autoridade prolatora da decisão que reexamina o mérito, possibilitando alterar sua própria decisão, de ofício ou ao acolher os argumentos delineados no anteparo. Por entendimento doutrinário e jurisprudencial, inadmite agravamento da pena quando a Administração verifica erro no proceder ou no julgar provocado pelo recurso do administrado que enseja a reforma, a nulidade, o esclarecimento ou a integração da decisão ${ }^{24}$.

Se mantida a condenatória, franqueia-se recurso no prazo de vinte dias à autoridade superior, dentro da área governamental sob sua jurisdição administrativa. Antes encaminhado à primeira autoridade recorrida para possibilitar o exercício da reconsideração restando, assim, esgotadas às vias recursais legalmente previstas ao infrator.

Destarte, percebe-se que o rito, o procedimento, a forma de desenvolvimento do processo abrangido no texto sanitário é um instrumento célere e equitativo que cumpre sua competência constitucional.

Importa saber que a vigilância sanitária não se limita ao poder de polícia, aliás, requer outras ferramentas, tais como a vigilância epidemiológica, monitoramento, pesquisa, educação, informações sanitárias e comunicação social ${ }^{11}$.

Desta feita, a opção sancionadora diante das especificidades do direito à saúde impõe-se, como desígnio, o viés educativo e punitivo para o alcance do resultado prático da lei.

\section{Meios de defesa admitidos na fase administrativa}

O AIS é o ato procedimental que se formaliza mediante um só documento que veicula regra sanitária consubstanciada em proposta de caráter sancionatório.

Já o PAS tem como pressuposto básico a plenitude de defesa ao autuado, segundo o qual assegura o contraditório (garantia do direito de resposta) postulando os motivos de fato e de direito em que se fundamenta e, ao final, suscitando a extinção ou a modificação da pretensão oposta. É feita pela impugnação escrita que inicia a fase contenciosa administrativa dos processos de fiscalização empreendidos.

É válido destacar que as pessoas jurídicas peticionam em seu nome, por seu administrador dotado da representatividade legal, conforme nomeado no contrato ou estatuto social ${ }^{25}$. 
ACarta Política ${ }^{5}$ aborda o processo administrativo no inc. LV do art. 50: "Aos litigantes, em processo judicial ou administrativo, e aos acusados em geral são assegurados o contraditório e ampla defesa, com os meios e recursos a ela inerentes". A partir desse enunciado constitucional, a Anvisa e as Visas oportunizam ao autuado, regularmente citado, manifestar-se do encargo sanitário, expondo suas alegações defensivas perante a autoridade julgadora apontada nos regimentos internos da instituição de cada esfera de governo.

É ônus do autuado carrear para o PAS todos os elementos ligados a irregularidade sanitária, de modo a comprovar a verdade formal da conduta. Enquanto às instituições sanitárias devem indicar, motivadamente, qual o ilícito atribuído, as circunstâncias em que ocorreu e demais requisitos mínimos indispensáveis à formalidade do AIS, sob pena de invalidação, com a redação e numeração dadas pelo art. 13, incisos I a VII, da Lei n. $6.437 / 1977^{1}$.

A peça defensória será escrita e conterá os fatos e fundamentos jurídicos que contrariem a autuação, assim como a especificação das provas que pretende produzir a seu favor, devidamente justificada.

Por vezes, o autuado insurge contra o AIS declarando que atendeu, durante a data limite estipulada na notificação, a exigência sanitária ou provou que o evento adverso não resultou em danos/lesões à saúde pública ou, ainda, que o mesmo apresenta vício insanável de ordem formal ou material.

Mantida a condenação, o caput do art. 30 da Lei n. $6.437 / 1977^{1}$ prevê uma segunda oportunidade recursal à autoridade hierarquicamente superior dentro da esfera governamental, à autoridade julgadora. No âmbito da União, à Diretoria Colegiada da Anvisa (art. 15, inc. VII, da Lei n. 9.782/19993); no âmbito dos Estados, dos Municípios e do Distrito Federal, pela respectiva secretaria de saúde ou órgão equivalente.

Esgotadas as vias recursais do PAS, caso mantenha a decisão de multa, o infrator tem 0 prazo de trinta dias para o pagamento mediante boleto ou depósito bancário, contados da data do recebimento da notificação por via postal com aviso de recebimento, ou outro meio válido que assegure a certeza de sua ciência para quitar a multa.

No caso de inadimplência, como medida coercitiva, acarreta a inscrição em dívida ativa e sua cobrança judicial dos débitos relativos à multa sanitária, nos termos da Lei n. 6.830/198026. É relevante destacar que 0 art. $6^{\circ}$ da Lei n. $10.522 / 2002^{27}$ impõe a obrigatoriedade de consulta prévia ao Cadastro Informativo de Créditos não Quitados do Setor Público Federal - Cadin pelos órgãos e entidades de regulação e fiscalização para uma série de processos de interesse dos infratores.

Aexistência de débitos inscritosno Cadin relativos às multas aplicadas pela Anvisa impede a concessão de incentivos fiscais/financeiros, a realização de operações de crédito e a celebração de contratos/ convênios/ajustes/acordos com desembolso que, em todos os casos, utilizem recursos públicos.

A receita, proveniente das multas resultantes de ações fiscalizadoras, será depositada, tomando como exemplo da Anvisa, na conta única do Tesouro Nacional, segundo disposição contida no art. $1^{\circ}, \S$ único, da RDC n. 222/2006 28 .

\section{Conclusão do processo sancionador}

Depois de realizado os seus atos, termos e formalidades, a rigor, o processo sanitário se 
extingue pela decisão da autoridade competente com os resultados que forem instituídos.

Face à letra da Lei n. 6.437/1977' resguardase o direito de defesa lato sensu no prazo de quinze dias (art. 22 combinado com o art. 30) direcionado à autoridade competente da Anvisa e das Visas (art.22, § $2^{\circ}$ ) e, caso seja mantida a decisão condenatória, assegura-se a apresentação do recurso administrativo-sanitário no prazo de vinte dias (art. 30, § único) à autoridade superior, na escala hierárquica da instituição sanitária.

As interposições da defesa/impugnação e do apelo pelo infrator que vise modificar ou extinguir decisão condenatória não surtirão os efeitos desejados após o esgotamento das vias recursais, situação em que a decisão se torna irrecorrível. A imutabilidade da decisão ocorre, também, na hipótese de que o autuado se mantenha silente com a fluência dos prazos recursais prescritos pela Lei (art. 29 e 37), ou ainda, recorra apenas da decisão primária $^{21}$.

A Lei n. 6.437/1977 contempla outras formas administrativas de extinção da punibilidade com o consequente fecho do PAS, a exemplo da condição do art. 21 que excepciona o princípio constitucional do contraditório:

Art. 21. As multas impostas em auto de infração poderão sofrer redução de $20 \%$ (vinte por cento) caso o infrator efetue o pagamento no prazo de 20 (vinte) dias, contados da data em que for notificado, implicando a desistência tácita de defesa ou recurso.

Esse dispositivo incentiva 0 recolhimento antecipado do crédito não-tributário, de forma a evitar a mora da finalização do PAS ao tempo em que recompensa o infrator com o pagamento a menor.
E apto para baixa e arquivamento a hipótese do art. 28:

Art. 28. Não sendo comprovada, através da análise fiscal, ou da perícia de contraprova, a infração objeto da apuração, e sendo considerado o produto próprio para o consumo, a autoridade competente lavrará despacho liberando-o e determinando o arquivamento do processo.

Outra forma de encerramento da punibilidade refere-se à inércia temporal da Anvisa e das Visas. Consuma-se a prescrição intercorrente com a perda de prosseguir nos elementos elucidativos da infração ou da perda do poder de punir, respectivamente, em decorrência da paralisação dos procedimentos administrativos por mais de um triênio, nos termos do art. $1^{\circ}, \S 1^{\text {o }}$ da Lei n. 9.873/199929. Outrossim, a prescrição quinquenal construída doutrinariamente de acordo com a celeridade na condução dos procedimentos administrativos, em antagonismo ao preceito do art. $38, \S 2^{\circ}$, da Lei n. 6.437/1977².

A propósito, inicia-se a contagem do prazo prescricional a partir da data da prática do ato ou, no caso de infração permanente ou continuada, do dia em que tiver cessado, conforme preceitua o art. $1^{\circ}$ da Lei n. 9.873/1999 ${ }^{29}$.

De qualquer forma, a finalização dos procedimentos encetados no PAS visa responsabilizar a pessoa física ou jurídica de suportar a sanção de uma consequência de sua ação antijurídica, típica e punível, cuja extensão de dano atinge o direito fundamental à saúde, consectário do direito à vida e concretizador do princípio da dignidade humana.

Além disso, cumpre ressaltar que do PAS pode advir um desfecho em via diversa que, em tese, extingue a punibilidade pecuniária do infrator, pelo 
risco de prescrição dos créditos não-tributários decorrente da multa sanitária, que enseja a redução da eficácia da ação de controle a cargo da Anvisa.

Cabe registrar que, no intuito de aprimorar o processo regulatório e mensurar o desempenho das agências reguladoras, o PAS é fiscalizado e avaliado pelo Tribunal de Contas da União (TCU), por competência constitucional ${ }^{5}$ descrita nos art. 70 e 71 .

Nesse mister, o Relatório de Monitoramento TC 022.631/2009- $0^{30}$ revelou que os procedimentos de fiscalização realizados pela Anvisa contemplaram a perda de receitas em face da baixa porcentagem de arrecadação das multas, o deficiente grau de inscrição de inadimplentes no Cadin, o reduzido percentual de ajuizamento de ações de cobrança e a necessidade de aprimoramento do Cadin.

\section{CONSIDERAÇÕES FINAIS}

A atuação administrativa da Anvisa e das Visas se insere na promoção e proteção da saúde pública, concentrado na racionalidade procedimental exteriorizada ao longo do PAS. Nesse passo, a intervenção efetiva dessas instituições sanitárias - nas atividades fins -, a exemplo do controle e da fiscalização de potenciais riscos, depende de leis processuais adequadas que garantam a exequibilidade das decisões das autoridades sanitárias.

O Texto Magno reconheceu a existência de um processo inerente ao exercício da função executiva por meio de determinação de garantias e direitos a ele relacionados. A vigência da Lei n. 6.437/1977', apesar de antiga e com alguns elementos decadentes, estabelece as bases do sistema processual sanitário, realçando a correlação entre Constituição e processo.
Mesmo que o arquétipo do feito sanitário se constitua na aplicação de medida punitiva, o PAS se perfaz no instrumento primordial para averiguar o nexo causal entre a conduta do autuado/infrator e do evento que deu causa à infração.

Em um Estado de Direito, o poder público se sujeita à lei eà observância dos direitos fundamentais, sendo importante atentar para o disposto no inc. LIV do art. $5^{\circ}$ da Lei Maior ${ }^{5}$ de que "ninguém será privado da liberdade ou de seus bens sem o devido processo legal", isto é, o ius puniendi estatal, está adstrito a uma série de obrigações e deveres.

Sob esta premissa, o PAS afigura-se como apropriado mecanismo processual utilizada pelas instituições sanitárias na repressão ao ilícito de quem lhe deu azo ou concorreu para sua prática, desde que a Anvisa atenda as exigências da auditoria governamental exercido pelo Órgão de contas quanto aos problemas descritos no aludido expediente.

No mais, conclui-se que a prolação de uma decisão administrativa confere efetividade à atuação estatal com o uso diligente do direito material e instrumental presente na Lei n. 6.437/1977', e a via processual sancionadora compatibiliza a garantia dos direitos e garantias processuais do autuado/ infrator com o bem intangível: saúde pública.

\section{REFERÊNCIAS}

1. Brasil. Lei n. 6.437, de 20 de agosto de 1977. Configura infrações à legislação sanitária federal e estabelece as sanções respectivas. [Acesso em 2012 out. 8]. Disponível em: <http://www.planalto.gov.br/ ccivil_03/leis/L6437.htm>

2. Brasil. Lei n. 8.080, de 19 de setembro de 1990. Lei Orgânica da Saúde. Dispõe sobre as condições para a promoção, proteção e recuperação da saúde, 
a organização e o funcionamento dos serviços correspondentes e dá outras providências. [Acesso em 2012 out. 30]. Disponível em: < http://www.planalto. gov.br/ccivil_03/leis/L8080.htm>

3. Brasil. Lei n. 9.782, de 26 de janeiro de 1999. Define o Sistema Nacional de Vigilância Sanitária, cria a Agência Nacional de Vigilância Sanitária, e dá outras providências. [Acesso em 2013 jan. 16] Disponível em: < http://www.planalto.gov.br/ccivil_03/leis/ L9782.htm>

4. Aith FMA. Consolidação do direito sanitário no Brasil. In: Costa AB, Sousa Júnior JG, Delduque MC, Oliveira MSC, Dallari SG. (Org.). O Direito Achado na Rua: Introdução Crítica ao Direito à Saúde. Brasília: UnB; 2008, p. 65-77 (4).

5. Brasil. Constituição da República Federativa do Brasil (1988). Diário Oficial [da] República Federativa do Brasil, Brasília, DF, 5 out. 1988. [Acesso em 2012 out. 8]. Disponível em: <http://www.planalto.gov.br/ ccivil_03/constituicao/constituicao.htm>

6. Mapelli Júnior R, Coimbra M, Matos YAPS. Direito sanitário. São Paulo: Ministério Público do Estado de São Paulo, Centro de Apoio Operacional das Promotorias de Justiça Cível e de Tutela Coletiva; 2012: 18.

7. Martins W. Direito à saúde: compêndio. Belo Horizonte: Fórum; 2008.

8. Rodrigues GA. Direito sanitário. In: Nunes Júnior VS (Coord.). Manual de Direitos Difusos. São Paulo: Verbatim; 2012: 89.

9. Carvalho C, Machado B, Timm LB. Direito sanitário brasileiro. São Paulo: Quartier Latin; 2004: 13.

10. Ferreira P. Responsabilidade civil do estado face às ações de vigilância sanitária em serviços de saúde. Brasília: Ministério da Saúde; 2006: 76.

11. Costa EA. Vigilância sanitária: proteção e defesa da saúde. 2a ed. aumentada. São Paulo: Sociedade Brasileira de Vigilância de Medicamentos; 2004.

12. Duarte Júnior RCF. A deslegalização no poder normativo das agências reguladoras. [Acesso em 2012 dez. 28]. Disponível em: <http://jusvi.com/ $\operatorname{artigos} / 42472>$.

13. Albuquerque VVC. Algumas contribuições ao debate sobre a função normativa do poder executivo e sua compatibilização com o sistema de tripartição de poderes e o princípio da legalidade. In: Romero LC, Delduque MC. (Org.). Produção normativa em saúde: políticas setoriais e regulação. Brasília: Senado Federal; 2012, p. 101-17.

14. Guerra S. Sistema único de saúde (SUS) e concepção de regulação de vigilância sanitária: 0 exercício descentralizado e reforçado do poder de polícia estatal. In: Asensi FD, Pinheiro R (Org.). Direito Sanitário. Rio de Janeiro: Elsevier, 2012; p. 162-80.

15. Aith FMA. Curso de direito sanitário: A Proteção do Direito à Saúde no Brasil. São Paulo: Quartier Latin; 2007.

16. Justen Filho M. Curso de direito administrativo. Belo Horizonte: Fórum; 2011.

17. Hirsch GJ.Fiscalização e processo administrativo sanitário. À luz da Constituição da República. Rio de Janeiro: Aide; 2003: 72.

18. Zymler B. Direito administrativo e controle. 3a ed. Belo Horizonte: Fórum; 2012: 27.

19. Olbertz K. O princípio do formalismo no processo administrativo. In: Medauar O, Schirato VR 
(Org.). Atuais Rumos do Processo Administrativo. São Paulo: Revista dos Tribunais; 2010, p. 215-38.

20. Brasil. Lei n. 9.784, de 29 de janeiro de 1999. Regula o processo administrativo no âmbito da Administração Pública Federal. [Acesso em 2013 jan. 22]. Disponível em: < http://www.planalto.gov.br/ ccivil_03/leis/L9784.htm>

21. Cartana AP. Processo administrativo sanitário. Porto Alegre: Alcance; 2000.

22. Kelsen H. Teoria geral do direito e do estado. São Paulo: Martins Fontes; 2000: 398.

23. Dias HP. Flagrantes do ordenamento jurídicosanitário. Brasília: Agência Nacional de Vigilância Sanitária; 2008: 274.

24. Oliveira RF. Infrações e sanções administrativas. 3a ed. atualizada e ampliada. São Paulo: Revista dos Tribunais; 2012.

25. Bedaque JRS. Efetividade do processo e técnica processual. São Paulo: Malheiros; 2007.

26. Brasil. Lei n. 6.830, de 22 de setembro de 1980. Dispõe sobre a cobrança judicial da Dívida Ativa da Fazenda Pública, e dá outras providências. [Acesso em 2013 jan. 22]. Disponível em: < http://www.planalto. gov.br/ccivil_03/leis/L6830.htm $>$.

27. Brasil. Lei n. 10.522, de 19 de julho de 2002. Dispõe sobre o Cadastro Informativo dos créditos não quitados de órgãos e entidades federais e dá outras providências. [Acesso em 2013 jan. 22]. Disponível em: <http://www.planalto.gov.br/ccivil_03/leis/2002/ L10522.htm>

28. Brasil. Resolução da Diretoria Colegiada RDC n. 222, de 28 de dezembro de 2006. Dispõe sobre os procedimentos de petição e arrecadação eletrônica no âmbito da Agência Nacional de Vigilância Sanitária - ANVISA e de suas Coordenações Estaduais e Municipais de Vigilância Sanitária e dá outras providências. [Acesso em 2013 jan. 22]. Disponível em: <http://www.anvisa.gov.br/legis/resol/2006/ rdc/222_06rdc.htm>

29. Brasil. Lei n. 9.783, de 23 de novembro de 1999. Estabelece prazo de prescrição para o exercício de ação punitiva pela Administração Pública Federal, direta e indireta, e dá outras providências. [Acesso em 2013 jan. 22]. Disponível em: <http://www.planalto.gov.br/ ccivil_03/leis/19873.htm>

30. Brasil. Tribunal de Contas da União. Plenário. Relatório de Monitoramento. TC 022.631/2009-0. Relator: Raimundo Carreiro. Brasília/DF. Acórdão aprovado em: 7 mar. 2012. [Acesso em 2013 jan. 24]. Disponível em: <http://portal2.tcu.gov.br/portal/pls/ portal/docs/1/2436837.PDF>

Artigo apresentado em: 23/02/2013 Artigo aprovado em: 16/03//2013 Artigo publicado no sistema em: 02/04/2013 